\title{
Breastfeeding and Risk of Rheumatoid Arthritis: A Systematic Review and Metaanalysis
}

\author{
Haiyan Chen, Jing Wang, Wang Zhou, Huabin Yin, and Meimei Wang
}

ABSTRACT. Objective. Previous studies have examined the association between breastfeeding and rheumatoid arthritis (RA), but their results were inconsistent. The aim of this study was to perform a metaanalysis to clarify the effect of breastfeeding on RA risk.

Methods. The PubMed, EMBASE, Chinese National Knowledge Infrastructure, and Wanfang databases were searched for relevant studies published up to September 10, 2014. Data were extracted, and multivariable-adjusted OR with $95 \% \mathrm{CI}$ were pooled in the random-effects model.

Results. A total of 6 studies were included in the metaanalysis (RA cases: 1672, sample size: 143,670). Overall, an inverse association between breastfeeding and RA was observed (OR $0.675,95 \%$ CI $0.493-0.924, p=0.014)$. In the subgroup analysis, decreased RA risk was also found in both breastfeeding 1-12 months (OR 0.783, 95\% CI 0.641-0.957, $\mathrm{p}=0.015$ ) and breastfeeding $>12$ months (OR $0.579,95 \%$ CI $0.462-0.726, \mathrm{p}<0.0005)$. Sensitivity analysis and cumulative analysis further strengthened the validity of the results. No publication bias was found in this metaanalysis.

Conclusion. This metaanalysis suggests that breastfeeding is associated with a lower risk of RA, no matter if breastfeeding time is longer or shorter than 12 months. (First Release July 15 2015; J Rheumatol 2015;42:1563-9; doi:10.3899/jrheum.150195)

Key Indexing Terms:

RHEUMATOID ARTHRITIS BREASTFEEDING RISK METAANALYSIS

Rheumatoid arthritis (RA) is the most common autoimmune inflammatory joint disease worldwide, affecting about $0.5 \%$ to $1 \%$ of the adult population ${ }^{1}$. RA, which is characterized by erosive symmetrical polyarthritis, can lead to joint destruction, disability, and a poor quality of life if not appropriately treated ${ }^{2}$. The prevalence of RA increases with age, and women are more susceptible to RA than $\mathrm{men}^{3}$. Although the etiology of RA remains elusive, epidemiological studies have suggested that hormonal factors are important in the development of $\mathrm{RA}^{4,5}$.

Breastfeeding, a common practice for adult women with newborns, is known to have multiple health benefits for the

From the Division of Rheumatology, Zhongda Hospital, School of Medicine, Southeast University, Nanjing; Department of Anatomy and Histoembryology, Xuzhou Medical College, Xuzhou; Department of Bone Tumor Surgery, Changzheng Hospital, Second Military Medical University, Shanghai, China.

Supported by the National Natural Science Foundation of China (81401355).

H. Chen, MM, Division of Rheumatology, Zhongda Hospital, School of Medicine, Southeast University; J. Wang, MD, Department of Anatomy and Histoembryology, Xuzhou Medical College, and Department of Bone Tumor Surgery, Changzheng Hospital, Second Military Medical

University; W. Zhou, PhD; H. Yin, PhD, Department of Bone Tumor Surgery, Changzheng Hospital, Second Military Medical University; M. Wang, MM, Division of Rheumatology, Zhongda Hospital, School of Medicine, Southeast University.

H. Chen, J. Wang, and W. Zhou contributed equally to this work and should all be considered as first authors.

Address correspondence to Dr. M. Wang, Rheumatology, Zhongda Hospital, 87 Dingjiaqiao Road, Nanjing, Jiangsu 210009, China.

E-mail:wmm3272142@163.com

Accepted for publication May 21, 2015. baby and may protect mothers against breast cancer and ovarian cancer $6,7,8,9$. Amelioration of RA has been observed during pregnancy with exacerbation in the postpartum period $^{10}$, and breastfeeding might play an important role in this apparent paradoxical result. The influence of breastfeeding on the risk of developing RA has been investigated in a number of studies, but their results were inconsistent, with increased risk, reduced risk, or no discernable effect reported $^{11,12,13,14,15,16,17,18,19}$.

Given a single study may lack the power to provide a reliable conclusion, metaanalysis is often used to enhance statistical power, and thus is likely to produce a more convincing conclusion. To our knowledge, there has been no metaanalysis investigating the association between breastfeeding and RA risk to date. Therefore, we performed quantitative metaanalyses to derive a more precise estimation of the relationship between them.

\section{MATERIALS AND METHODS}

Publication search. Observational studies (case-control, nested case-control, and cohort studies) on breastfeeding and RA development were included in our metaanalysis, irrespective of language or publication status and article type. Two investigators (Chen and Zhou) conducted a comprehensive, computerized literature search through the PubMed, EMBASE, Chinese National Knowledge Infrastructure (CNKI), and Wanfang databases up to September 10, 2014. The following search terms were used: "rheumatoid arthritis" or "RA" and "breastfeeding" or "breast feeding." We also perused the reference lists of selected research papers and reviews to identify additional relevant studies.

Inclusion and exclusion criteria. Two authors (Chen and Wang) independently evaluated all of the studies retrieved based on the prespecified selection

Personal non-commercial use only. The Journal of Rheumatology Copyright @ 2015 . All rights reserved. 
criteria. Eligible studies met the following inclusion criteria: (1) any type of observational study investigating the relationship between breastfeeding and RA development, (2) reported the relative risk (RR) or and its $95 \%$ CI for the association between breastfeeding and RA development, and (3) included patients diagnosed with RA based on the American College of Rheumatology criteria for RA. Studies were excluded if any of the following existed: (1) not relevant to breastfeeding or RA risk; (2) did not contain adequate data for inclusion; (3) included duplicate data; (4) was about juvenile RA; (5) was not in English; (6) was an editorial, review, or abstract; and (7) had unadjusted data. If more than 1 study used the same cases, the 1 with the most comprehensive population was included.

Data extraction. Three investigators (Chen, Wang, and Yin) independently extracted data from the included studies. The following information was collected from each study: first author's name, year of publication, original country, ethnicity, age group, sample size, and subgroup information. We verified the accuracy of the data by comparing collection forms between investigators. If different results were generated, the full text of the article was checked.

Statistical analysis. The strength of the associations between breastfeeding and RA risk was measured by OR and 95\% CI. The random-effects model was used. The statistical significance of summary OR was determined with the $\mathrm{Z}$ test. Heterogeneity was assessed by the $\mathrm{I}^{2}$ statistic. We considered low, moderate, and high $\mathrm{I}^{2}$ values to be $25 \%, 50 \%$, and $75 \%$, respectively. A chi-square-based $\mathrm{Q}$ test was also performed to check the between-study heterogeneity. To explore the main source of heterogeneity, subgroup analyses were performed by breastfeeding time. To assess the stability of the metaanalysis, 1-way sensitivity analyses were carried out. Funnel plot was used to assess potential publication bias. The Egger test was used to quantitatively assess publication bias. All statistical tests were performed using STATA 12.0 software (Stata Corp.). A p value of $<0.05$ was considered significant.

\section{RESULTS}

Study characteristics. The result of the study selection process is shown in Figure 1. The initial search produced 169 studies from the PubMed, EMBASE, CNKI, and Wanfang databases. After exclusion of duplicates, 72 potentially eligible studies were selected. After detailed evaluations, 10 studies were full-text reviewed and 4 studies were excluded (3 studies used duplicate data ${ }^{17,18,19}$ and 1 had no relation to RA onset, but with severity of $\mathrm{RA}^{20}$ ). Finally, in the current study, 6 eligible studies $11,12,13,14,15,16$ that met the inclusion criteria were included in our metaanalysis. There were 5 studies on whites and 1 study on Asians. There were 3 case-control studies containing 241 RA cases and 859 controls, and 3 cohort studies containing 1431 RA cases from 142,570 participants. Four studies had subgroup analysis on breastfeeding time, and 3 of them could be selected into our subgroup analysis. The characteristics of each study included in this metaanalysis are shown in Table 1.

Quantitative synthesis. All of the main results of the metaanalysis are shown in Table 2. Overall, an inverse association between breastfeeding and RA risk was found (breastfeeding ever vs never: OR 0.675 , 95\% CI $0.493-0.924$; Figure 2). Next, we performed an analysis on data stratified by breastfeeding time and ethnicity with the attempt to search for possible factors that might affect the results. In the subgroup analysis of breastfeeding time, protective effect of breastfeeding on RA development was also found in breastfeeding 1-12 months (breastfeeding 1-12 vs never: OR $0.783,95 \%$ CI $0.641-0.957)$ and breastfeeding $>12$ months (breastfeeding $>12$ vs never: OR 0.579 , 95\% CI $0.462-0.726)$. In the subgroup analysis by ethnicity, no

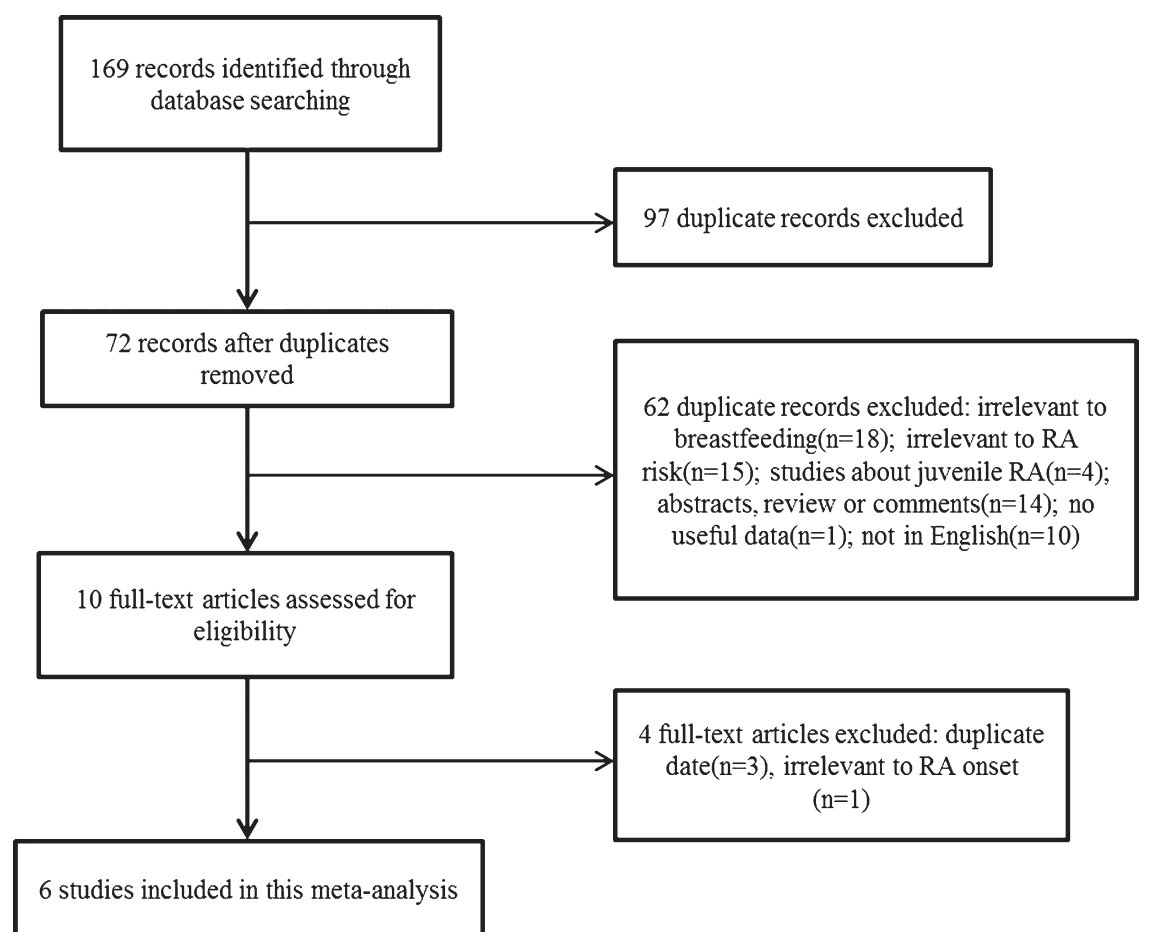

Figure 1. Flow of study identification, inclusion, and exclusion. RA: rheumatoid arthritis. 
Table 1. General characteristics of the included studies of breastfeeding and risk of RA.

\begin{tabular}{|c|c|c|c|c|c|c|c|c|c|c|}
\hline First Author & $\mathrm{Yr}$ & Country & $\begin{array}{l}\text { Type } \\
\text { of Study }\end{array}$ & Ethnicity & $\begin{array}{c}\text { Age } \\
\text { Group, Yrs }\end{array}$ & No. Cases & $\begin{array}{l}\text { Sample } \\
\text { Size, } \mathrm{n}\end{array}$ & $\begin{array}{c}\text { Diagnosis } \\
\text { Method }\end{array}$ & Adjusted Factors & Subgroup \\
\hline Brennan, et al ${ }^{11}$ & 1994 & England & $\begin{array}{l}\text { Case- } \\
\text { control }\end{array}$ & White & $16-45$ & 35 & 70 & $\begin{array}{l}\text { ACR 1987, } \\
\text { rheumatologists }\end{array}$ & $\begin{array}{l}\text { Social class, parity, } \\
\text { and OC use. }\end{array}$ & None \\
\hline Karlson, et al $^{12}$ & 2004 & USA & Cohort & White & $30-55$ & 674 & 121,700 & $\begin{array}{l}\text { ACR } 1987, \\
\text { medical record } \\
\text { review }\end{array}$ & $\begin{array}{l}\text { Age, smoking, BMI, parity, } \\
\text { OC use, menstrual cycle regularity, } \\
\text { and postmenopausal hormone use. }\end{array}$ & $\begin{array}{l}\leq 3 \mathrm{mos}, 4-11 \mathrm{mos} \\
12-23 \mathrm{mos}, 24 \mathrm{mos}\end{array}$ \\
\hline Berglin, et al ${ }^{14}$ & 2010 & Sweden & $\begin{array}{l}\text { Case- } \\
\text { control }\end{array}$ & White & $20.1-68.4$ & 70 & 350 & $\begin{array}{l}\text { ACR 1987, } \\
\text { rheumatologists }\end{array}$ & $\begin{array}{l}\text { IgM-RF-positive/negative, ACPA-positive } \\
\text { negative, PTPN22 1858T variant yes/no, } \\
\text { and no. biological children. }\end{array}$ & $\begin{array}{l}0-3 \mathrm{mos}, 4-8 \mathrm{mos} \\
9-16 \mathrm{mos}, \geq 17 \mathrm{mos}\end{array}$ \\
\hline Lahiri, et al ${ }^{15}$ & 2014 & UK & Cohort & White & $40-79$ & 102 & 13,772 & $\begin{array}{l}\text { ACR 1987, } \\
\text { rheumatologists }\end{array}$ & $\begin{array}{l}\text { Age, smoking, BMI, alcohol, } \\
\text { social class, diabetes mellitus, and parity. }\end{array}$ & None \\
\hline
\end{tabular}

RA: rheumatoid arthritis; ACR: American College of Rheumatology; OC: oral contraceptive; BMI: body mass index; IgM: immunoglobulin M; RF: rheumatoid factor; ACPA: anticitrullinated protein antibodies.

Table 2. Results of metaanalysis for breastfeeding and RA risk.

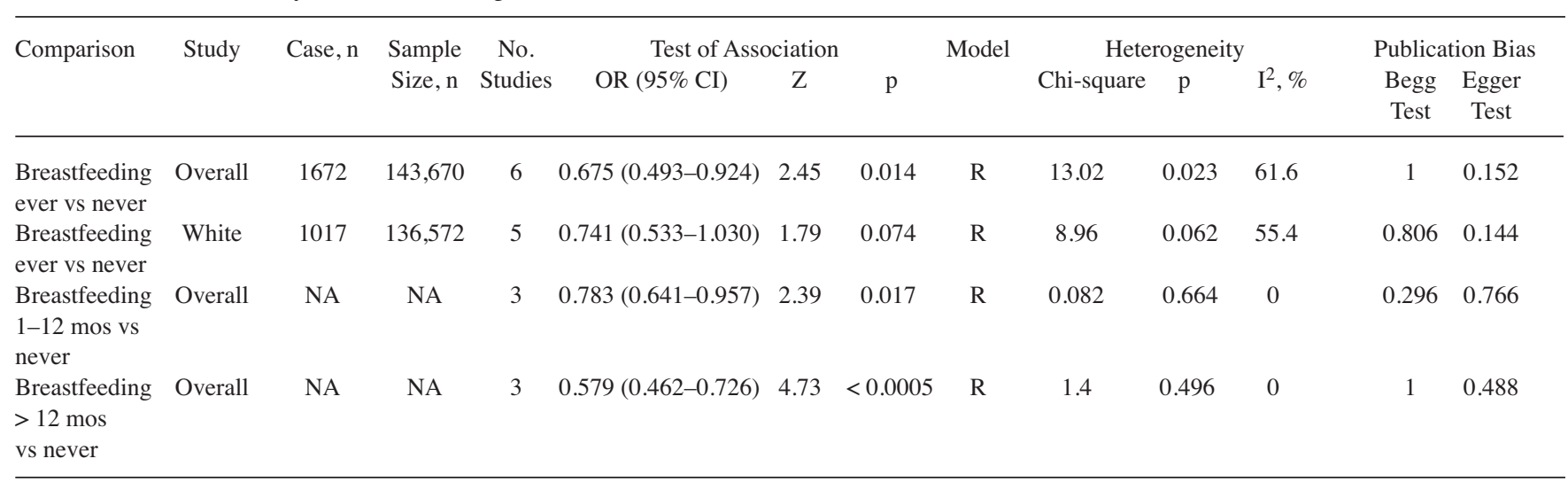

RA: rheumatoid arthritis; NA: not available; R: random effects.

significant associations were found among whites (OR 0.741, 95\% CI 0.533-1.030, $\mathrm{p}=0.074)$.

Heterogeneity analysis. Significant heterogeneity existed in 1 model (breastfeeding ever vs never: $\mathrm{p}=0.023, \mathrm{I}^{2}=61.2 \%$ ). No heterogeneity existed in the other 3 models (breastfeeding for whites, ever vs never: $\mathrm{p}=0.062, \mathrm{I}^{2}=55.4 \%$; breastfeeding 1-12 mos vs never: $\mathrm{p}=0.664, \mathrm{I}^{2}=0 \%$; breastfeeding $>12$ mos vs never: $\mathrm{p}=0.496, \mathrm{I}^{2}=0 \%$ ). The random-effect models were used in all models.

Sensitivity analyses and publication bias. Sensitivity analyses were performed to assess whether each individual study can affect the final results by using the Begg test and Egger test. Neither the Begg test nor the Egger test provided any obvious evidence of publication bias (Table 2). The shapes of the funnel plots appeared to be symmetrical in all genetic models (Figure 3 ). These results showed that no individual study affected the final results in diverse genetic models using the exclusion method step by step.

\section{DISCUSSION}

Our study incorporates the available published observational studies including 1672 patients with RA, and aims to provide a qualitative estimate of the association between breastfeeding and RA risk. A total of 6 studies were systematically evaluated, and an inverse association between breastfeeding and RA development was found in the overall study population. In the subgroup analysis of breastfeeding time, we found that both breastfeeding 1-12 months and breastfeeding > 12 months could significantly decrease the development of RA. In the subgroup analysis by ethnicity, no significant association between breastfeeding and RA risk was found in whites. Only 1 study investigated the associ-

$$
\text { Personal non-commercial use only. The Journal of Rheumatology Copyright } \odot \text { 2015. All rights reserved. }
$$




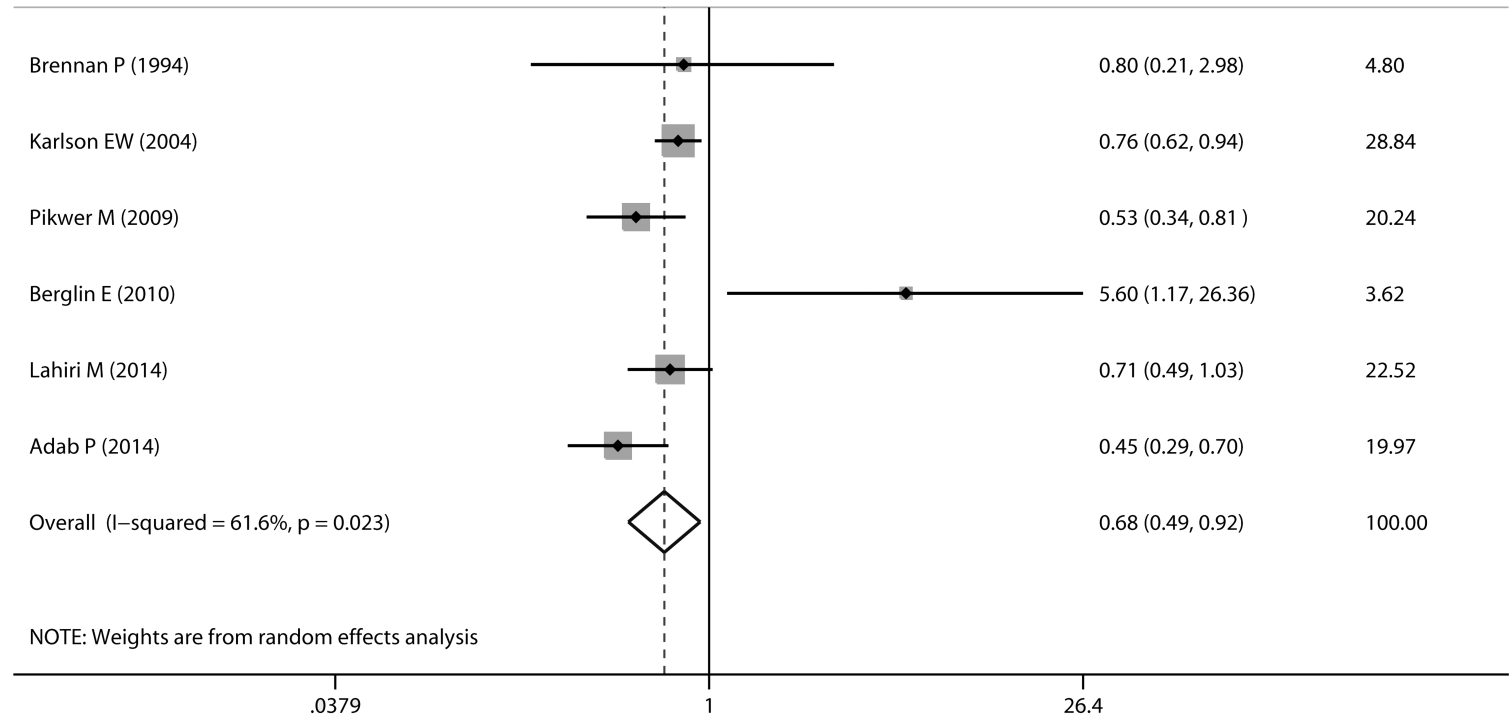

2B

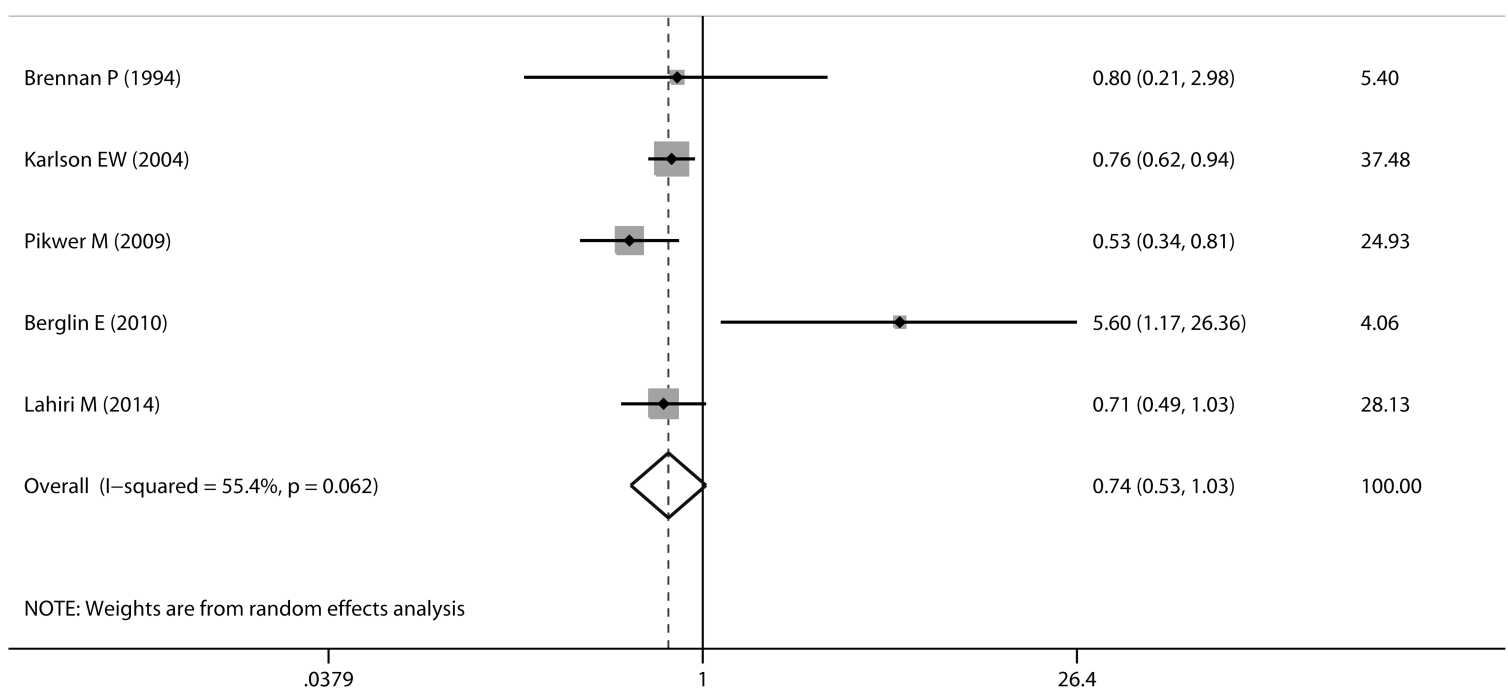

Figure 2. Metaanalysis of the association between breastfeeding and RA risk. A. Metaanalysis of breastfeeding on RA risk. B. Metaanalysis of breastfeeding on RA risk in whites. C. Metaanalysis of the association between breastfeeding 1-12 months and RA risk. D. Metaanalysis of the association between breastfeeding $>12$ months and RA risk. RA: rheumatoid arthritis.

ation between breastfeeding and RA risk in Asians, and none of the articles were about Africans. Thus, more studies with Asians or Africans are still needed.
Breastfeeding is known to have multiple health benefits for the baby and may protect mothers against breast cancer and ovarian cancer ${ }^{6,7,8,9,21,22}$. A number of studies concerning 


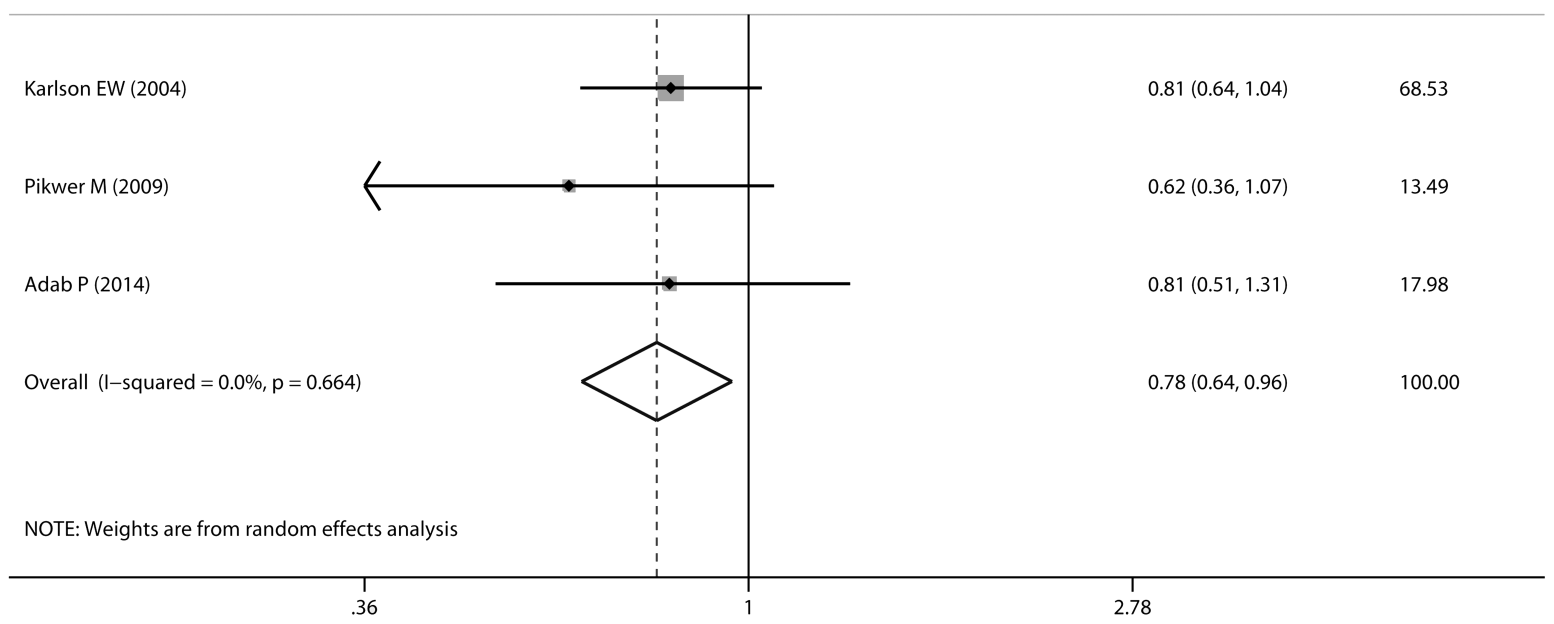

2D

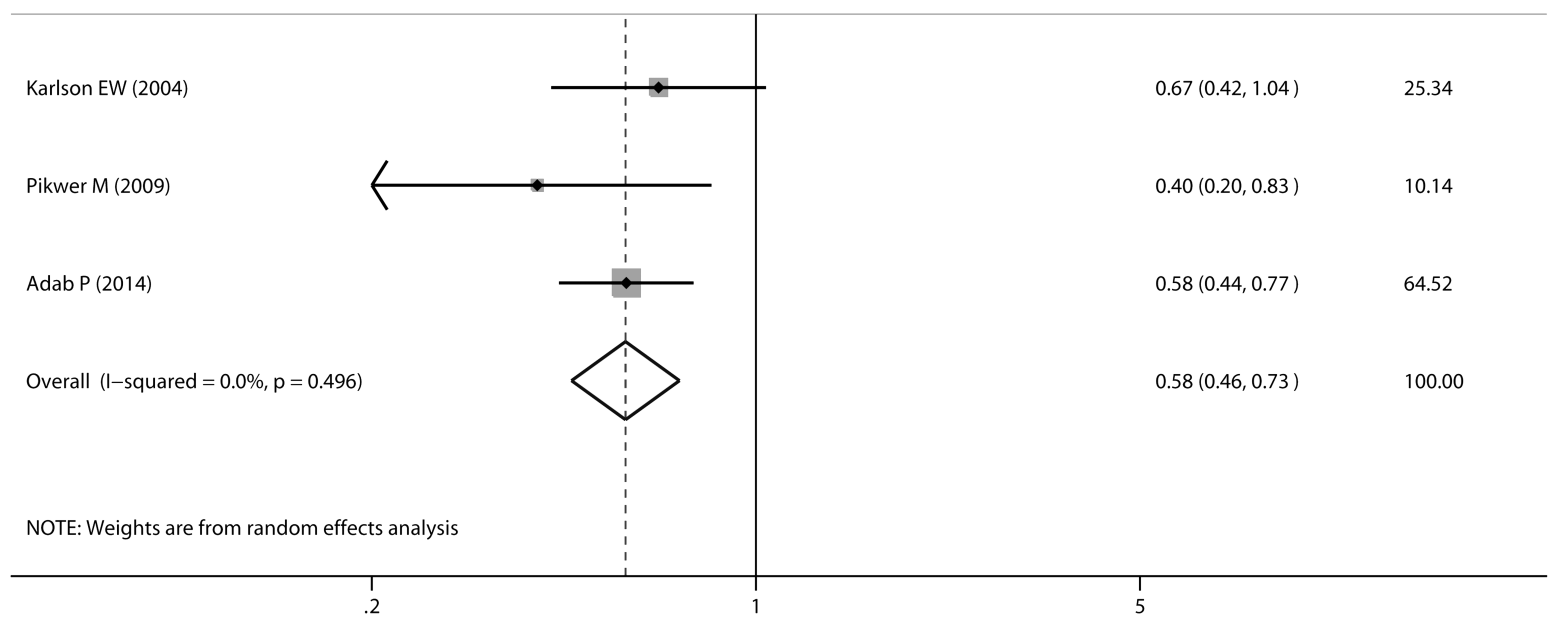

Figure 2. Continued

the influence of breastfeeding on the risk of RA have yielded conflicting results ${ }^{11,12,13,14,15,16,17,18,19}$. Berglin, et al ${ }^{14}$ conducted a study restricted to patients with early RA who developed RA within 1 year and reported that breastfeeding increased the risk of developing RA. Possible explanations supporting the results of increased risk for RA with breast- 
A
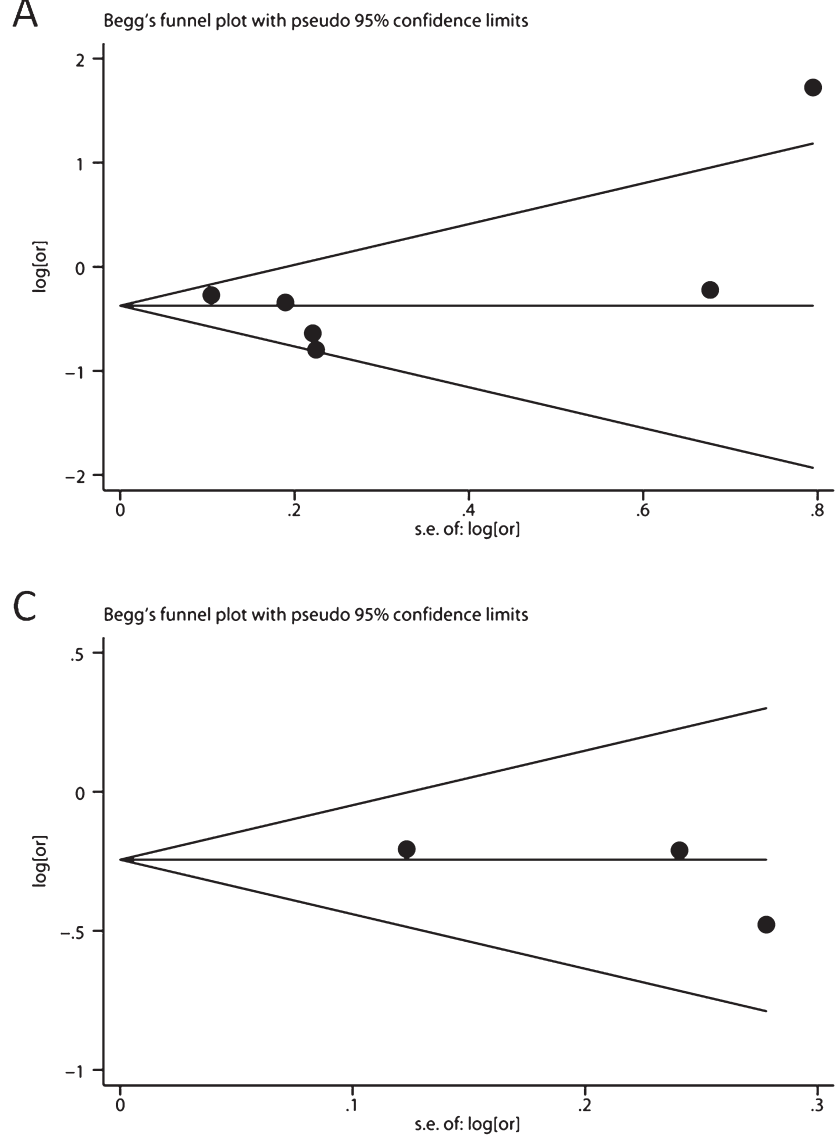
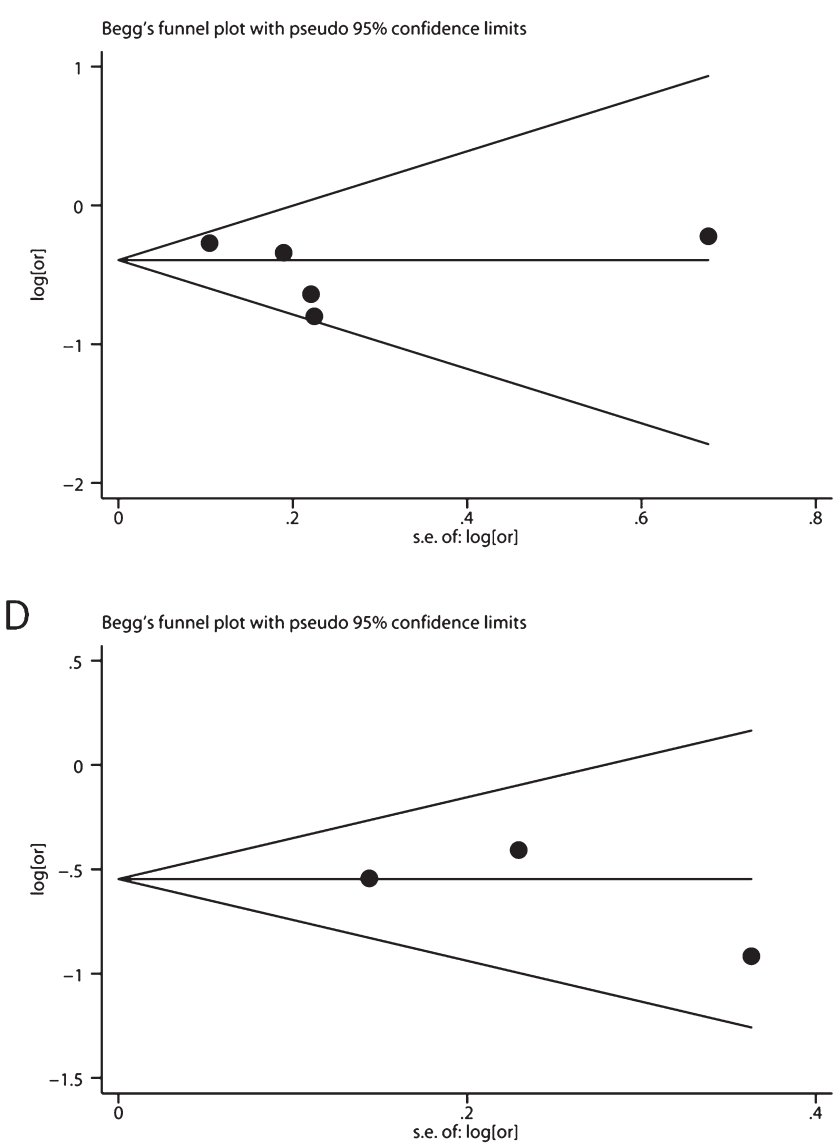

Figure 3. Funnel plots for breastfeeding and RA risk. A. Effect of breastfeeding on general RA risk. B. Effect of breastfeeding on RA risk in whites. C. Effect of breastfeeding 1-12 months and RA risk. D. Effect of breastfeeding > 12 months and RA risk. RA: rheumatoid arthritis.

feeding could be the high serum levels of prolactin during breastfeeding that have been shown to have immunostimulatory effects and could lead to the development of RA by several mechanisms ${ }^{23}$. In contrast, Karlson, et al and Pikwer, et al reported a significantly reduced risk of RA in women with longterm breastfeeding ${ }^{12,13}$. One proposed mechanism for this protective effect is through antiinflammatory progesterone, which rises during pregnancy and continues to be high during breastfeeding ${ }^{24}$. Another proposed mechanism is related to cortisol, which also has antiinflammatory effects and has been shown to be significantly higher among postmenopausal women who have breastfed ${ }^{25}$.

The antiinflammatory effects of pregnancy-related hormones and the short-term beneficial effects in RA are well known, but the longterm effects of pregnancy and the benefits of breastfeeding are less clear ${ }^{26}$. Our metaanalysis of the overall study suggested a protective effect of breastfeeding on RA risk. There were also controversies about the effect of breastfeeding time in the literature. Karlson, et al and Pikwer, et al considered a significant trend toward lower risk for RA with a longer duration of breastfeeding, especially those $\geq 13$ months ${ }^{12,13}$. Jorgensen, et al found that the duration of breast- feeding had no influence on the risk of developing RA ${ }^{20}$. Our results suggested that both breastfeeding 1-12 months and breastfeeding $>12$ months had a protective effect on RA development. Unfortunately, we could not make further comparison to determine which duration was better because of the lack of source data.

Results from this metaanalysis were stable and reliable. First, sensitivity analyses and cumulative metaanalyses revealed that the results were robust. Second, there was no significant heterogeneity in most of the comparisons. Third, the funnel plot and Egger tests found no significant publication bias. However, some limitations should be addressed. First, as a metaanalysis about observational studies, we could not resolve problems with confounding factors inherent in the included primary studies. Most of the included studies adjusted only for age and oral contraceptive use, and other important confounding factors were not standard, such as social class, smoking, genetic factors, parity, and alcohol consumption. Second, although there was no publication bias by the Begg funnel plot and Egger test, bias of selection may have occurred because only studies in English were selected.

To our knowledge, this was the first comprehensive 
metaanalysis to assess the relationship between breastfeeding and RA risk. This metaanalysis found that breastfeeding was moderately associated with a decreased risk of RA, no matter if the breastfeeding time was longer or shorter than 12 months.

\section{REFERENCES}

1. Gabriel SE, Crowson CS, O'Fallon WM. The epidemiology of rheumatoid arthritis in Rochester, Minnesota, 1955-1985. Arthritis Rheum 1999;42:415-20.

2. Murata K, Furu M, Yoshitomi H, Ishikawa M, Shibuya H, Hashimoto M, et al. Comprehensive microRNA analysis identifies miR-24 and miR-125a-5p as plasma biomarkers for rheumatoid arthritis. PLoS One 2013;8:e69118.

3. Tobón GJ, Youinou P, Saraux A. The environment, geo-epidemiology, and autoimmune disease: rheumatoid arthritis. J Autoimmun 2010;35:10-4.

4. Symmons DP, Barrett EM, Bankhead CR, Scott DG, Silman AJ. The incidence of rheumatoid arthritis in the United Kingdom: results from the Norfolk Arthritis Register. Br J Rheumatol 1994;33:735-9.

5. Oliver JE, Silman AJ. Risk factors for the development of rheumatoid arthritis. Scand J Rheumatol 2006;35:169-74.

6. Scariati PD, Grummer-Strawn LM, Fein SB. A longitudinal analysis of infant morbidity and the extent of breastfeeding in the United States. Pediatrics 1997;99:E5.

7. Oddy WH, Holt PG, Sly PD, Read AW, Landau LI, Stanley FJ, et al. Association between breast feeding and asthma in 6 year old children: findings of a prospective birth cohort study. BMJ 1999;319:815-9.

8. Collaborative Group on Hormonal Factors in Breast Cancer. Breast cancer and breastfeeding: collaborative reanalysis of individual data from 47 epidemiological studies in 30 countries, including 50302 women with breast cancer and 96973 women without the disease. Lancet 2002;360:187-95.

9. Danforth KN, Tworoger SS, Hecht JL, Rosner BA, Colditz GA, Hankinson SE. Breastfeeding and risk of ovarian cancer in two prospective cohorts. Cancer Causes Control 2007;18:517-23.

10. Liao KP, Alfredsson L, Karlson EW. Environmental influences on risk for rheumatoid arthritis. Curr Opin Rheumatol 2009;21:279-83.

11. Brennan P, Silman AJ. An investigation of gene-environment interaction in the etiology of rheumatoid arthritis. Am J Epidemiol 1994;140:453-60.

12. Karlson EW, Mandl LA, Hankinson SE, Grodstein F. Do breast-feeding and other reproductive factors influence future risk of rheumatoid arthritis? Results from the Nurses' Health Study. Arthritis Rheum 2004;50:3458-67.
13. Pikwer M, Bergström U, Nilsson JA, Jacobsson L, Berglund G, Turesson C. Breast feeding, but not use of oral contraceptives, is associated with a reduced risk of rheumatoid arthritis. Ann Rheum Dis 2009; 68:526-30.

14. Berglin E, Kokkonen H, Einarsdottir E, Agren A, Rantapää Dahlqvist S. Influence of female hormonal factors, in relation to autoantibodies and genetic markers, on the development of rheumatoid arthritis in northern Sweden: a case-control study. Scand J Rheumatol 2010;39:454-60.

15. Lahiri M, Luben RN, Morgan C, Bunn DK, Marshall T, Lunt M, et al. Using lifestyle factors to identify individuals at higher risk of inflammatory polyarthritis (results from the European Prospective Investigation of Cancer-Norfolk and the Norfolk Arthritis Register-the EPIC-2-NOAR Study). Ann Rheum Dis 2014;73:219-26.

16. Adab P, Jiang CQ, Rankin E, Tsang YW, Lam TH, Barlow J, et al. Breastfeeding practice, oral contraceptive use and risk of rheumatoid arthritis among Chinese women: the Guangzhou Biobank Cohort Study. Rheumatology 2014;53:860-6.

17. Sparks JA, Chen CY, Hiraki LT, Malspeis S, Costenbader KH, Karlson EW. Contributions of familial rheumatoid arthritis or lupus and environmental factors to risk of rheumatoid arthritis in women: A prospective cohort study. Arthritis Care Res 2014;66:1438-46.

18. Brennan P, Silman A. Breast-feeding and the onset of rheumatoid arthritis. Arthritis Rheum 1994;37:808-13.

19. Pikwer M, Bergström U, Nilsson JÅ, Jacobsson L, Turesson C. Early menopause is an independent predictor of rheumatoid arthritis. Ann Rheum Dis 2012;71:378-81.

20. Jorgensen C, Picot MC, Bologna C, Sany J. Oral contraception, parity, breast feeding, and severity of rheumatoid arthritis. Ann Rheum Dis 1996;55:94-8.

21. Howie PW, Forsyth JS, Ogston SA, Clark A, Florey CD. Protective effect of breast feeding against infection. BMJ 1990;300:11-6.

22. Gartner LM, Morton J, Lawrence RA, Naylor AJ, O'Hare D, Schanler RJ, et al; American Academy of Pediatrics Section on Breastfeeding. Breastfeeding and the use of human milk. Pediatrics 2005;115:496-506.

23. Orbach H, Shoenfeld Y. Hyperprolactinemia and autoimmune diseases. Autoimmun Rev 2007;6:537-42.

24. Szekeres-Bartho J, Barakonyi A, Par G, Polgar B, Palkovics T, Szereday L. Progesterone as an immunomodulatory molecule. Int Immunopharmacol 2001;1:1037-48.

25. Lankarani-Fard A, Kritz-Silverstein D, Barrett-Connor E, Goodman-Gruen D. Cumulative duration of breast-feeding influences cortisol levels in postmenopausal women. J Womens Health Gend Based Med 2001;10:681-7.

26. Straub RH, Buttgereit F, Cutolo M. Benefit of pregnancy in inflammatory arthritis. Ann Rheum Dis 2005;64:801-3. 